\title{
Miranda Estrampes, Manuel; Cerda San Martín, Rodrigo y Hermosilla Iriarte, Francisco (2012) Práctica de la prueba en el Juicio Oral. Su valoración y el estándar del "más allá de toda duda razonable”. Santiago: Editorial Librotecnia, 445 pp.
}

Dos jueces y un fiscal ${ }^{1}$, sin perjuicio de sus cargos y grados académicos, informan esta obra de vocación eminentemente pragmática que viene a enriquecer el acervo de las obras nacionales que versan sobre una disciplina definitivamente no neutral: derecho procesal penal. Surgida desde las propias entrańas del aparato de justicia criminal, estos actores principales de la misma realizaron un trabajo pocas veces visto: fueron capaces de formularse cuarenta y un interrogantes sobre intrincados problemas referidos a la dinámica de la prueba en sede procesal penal, encargándose aleatoriamente cada uno de una respuesta, manifestando su opinión crítica y públicamente previa deliberación de todos ellos entre sí (p.18). El producto es el que está a disposición del lector, sistematizado según los problemas propios de la aportación, admisión, producción y valoración de la prueba.

No es casual que el honor de su prólogo haya recaído en la profesora María Inés Horvitz, de cuyo manual, escrito en coautoría con Julián López Masle, se han servido numerosas generaciones de estudiantes de Derecho para su aprendizaje. Al igual que esta, tanto Cerda San Martín como Hermosilla Iriarte han sido perseverantes con el mismo designio, educar a través de sus obras sobre el sistema de enjuiciamiento criminal. Esta vez, en conjunto con Miranda Estrampes -quien destaca por la misma razón-, no dejan apacible al receptor, por cuanto los conocimientos y las experiencias adquiridas por los mismos decanta en una reflexión sobre el fenómeno probatorio de realidad palpable y verosímil ${ }^{2}$.

1 Francisco Hermosilla Iriarte se desempeña como juez del Tribunal de Juicio en lo Penal de Valparaíso; Rodrigo Cerda San Martín fue juez del Tribunal de Juicio oral en lo Penal de Talca, sirviendo actualmente el cargo de Ministro de la Corte de Apelaciones de Arica. Manuel Miranda Estrampes sirve el cargo de fiscal ante el Tribunal Constitucional Español.

2 De manera enunciativa señalamos que son obra de estos autores: a) Hermosilla Iriarte, Francisco (2006) Apuntes sobre la prueba en el Código Procesal Penal. Santiago: Librotecnia; (2011) ¿Cuándo debiéramos estimar eficaces las declaraciones prestadas por el coimputado?, tesis de magíster en Derecho (LEGUM MAGÍSTER) Escuela de Derecho Universidad de Valparaíso. Valparaíso: inédita; b) Cerda San Martín, Rodrigo (2003) Etapa intermedia: juicio oral y recursos. Santiago: Librotecnia; (2005) Manual del nuevo sistema de justicia criminal. Santiago: Librotecnia; c) Obras en conjunto de ambos autores citados son: (2003) El procedimiento abreviado. Santiago: Editorial Metropolitana; (2008) El Código procesal penal: comentarios, concordancias y jurisprudencia. $3^{\text {a }}$ edición. Santiago: Librotecnia; d) Miranda Estrampes, Manuel (1997) La minima actividad probatoria en el Proceso Penal. Barcelona: Editorial Bosch; (2004) El concepto de prueba ilicita y su tratamiento en el Proceso Penal. Barcelona: Editorial Bosch. 
La estructura de este trabajo viene dada por veintitrés preguntas sobre la práctica de la prueba en el juicio oral: ocho sobre las facultades probatorias del Tribunal de Juicio Oral en lo Penal; siete sobre la valoración de la prueba y el estándar probatorio; culminando con tres sobre la motivación fáctica de las sentencias. En las treinta y un primeras tienen participación los tres autores. Los dos últimos ámbitos abordados, en cambio, se dirimen en exclusiva por trabajos de Miranda y Cerda San Martín.

Tratando de sobrellevar las limitadas fronteras de esta recensión -que me impiden deslizar un comentario sobre cada una de las respuestas dadas-, destacaré a continuación respecto de cada autor, los que me parecieron sus principales aciertos, esperando que el empeño resulte demostrativo del conjunto.

Partiendo por el doctor Barcelonés, Miranda Estrampes, debo señalar que tuvo a su cargo dar respuestas a consultas de complejidad no menor $^{3}$. La tarea fue cumplida de satisfactoria manera, manejando las fuentes patrias con destreza destacable. Esto es palpable cuando trata por ejemplo, en la primera parte del libro, sobre la admisibilidad de los testigos anónimos en general, para luego cristalizarlo en nuestro sistema y su consiguiente desmedro para el derecho de defensa, lo que como contraprestación, en su concepto, debe necesariamente repercutir en el momento de la valoración de esta prueba, descartándose la posibilidad de que pueda reunir el mérito de ser la única o decisiva prueba de cargo determinante de una condena (pp. 93-94). Hacemos énfasis en que ello no tendría mayor asidero si no contásemos con las leyes $\mathrm{N}^{\text {os }} 18.314$ y 20.000, que en este último caso no solo contempla la existencia de la figura, sino que va más allá, al permitir que sea el órgano persecutor quien imponga su poderío -en términos de conceder el anonimato- de manera vinculante para el tribunal, soslayando la jurisdiccionalidad y el control de la necesidad de la medida (pp. 90-91).

De la misma manera sobresale la respuesta a la pregunta número veinte, la que asesta un golpe a un problema ínsito en nuestro Código Procesal Penal, el que si bien dispensa explícitamente al testigo-pariente del deber de declarar en el juicio oral, no se pronuncia sobre lo mismo durante la fase de investigación. Con este trabajo queda dogmáticamente establecido que la facultad de abstención de declarar del testigo-pariente corre para todas las fases del procedimiento aunque no se diga explícitamente, ello por imperativo dogmático y constitucional, toda vez que debe aplicarse directamente en estos casos la norma de máxima jerarquía del artículo 19 No 7 letra f) de la Constitución Política de la República, sin perjuicio de otros criterios ortodoxos contenidos en diligencias de inves-

Las preguntas y respuestas a que nos referimos son las otorgadas a los $\mathrm{N}^{\text {os }} 7$ (pp. 83-95), 20 (pp. 205-212) y 37 (pp. 357-368). 
tigación especialmente lesivas para los derechos fundamentales, como el caso de la incautación. Lo expuesto, sea que el testigo reúna en sí mismo la calidad de pariente-víctima, sea que su denuncia haya dado inicio al procedimiento (p. 208).

Del tercer capítulo de la obra, compuesto -como dijimos- únicamente por sus respuestas, asoma un tema de aquellos que en apariencia no impresionan más de lo que haría un grano de mostaza, pero que luego de cesado el espejismo reclaman los fueros perdidos en forma directamente proporcional a su importancia y extensión: la prueba cientifica y el problema de su valoración por el juez penal. La tarea en este recodo, según lo expresado por el autor -quien cita sobre el tópico trabajos de tanta pertinencia como los de Taruffo y Gascón-, parte por trabajar en desmitificar la infalibilidad de estas probanzas (sobredimensión epistémica y semántica de la prueba), acentuando los criterios de admisibilidad científica de las pruebas periciales, evitando que la junk science o mala ciencia ingrese al proceso. Sobre lo mismo resulta ilustrativa la doctrina Daubert asentada por la Corte Suprema Federal norteamericana (u otros análogos o complementarios), que proporciona criterios de evaluación de la confiabilidad de las pruebas científicas con vocación de regir tanto en la oportunidad procesal de la admisión de la prueba como también en la posterior valoración, teniendo perfectamente cabida en Chile a la luz de los artículos 272, 297 y 316 del Código Procesal Penal.

Sobre Hermosilla y Cerda San Martín, los parabienes son similares. La distinción en este caso proviene del responder crítica, fundada y públicamente lo que otros con su investidura y en su lugar callan. En este sentido, compartamos o no su adherencia con alguna doctrina, debe reconocérseles el que continúan por un camino cuya huella precedente rememora la pluma de notables jueces que, faltos de democracia y de derechos fundamentales, se atrevieron a escribir.

Destaco por lo mismo, respecto de Hermosilla Iriarte ${ }^{4}$, las respuestas proporcionadas a las preguntas números tres y diez, ambas sobre un trasfondo común: las declaraciones del imputado prestadas durante el desarrollo del procedimiento penal ante distintos agentes, siendo la más relevante aquella que tiene lugar frente a un policía. Sobre ello sistematiza distintas hipótesis, algunas visibles por estar contenidas en el Código Procesal Penal, otras ocultas, que exigen para su apreciación sumergirse en la realidad forense. La inquietud que sirve de denominador común es la posible utilización como prueba de cargo de aquel receptor de la decla-

\footnotetext{
4 Destacamos las respuestas dadas a las preguntas $N^{o s} 3$ (pp. 43-61) y 10 (pp. 116-142), se recomienda también la lectura de las respuestas otorgadas a las preguntas Nos 18 (pp. 183196) y 25 (pp. 243-265).
} 
ración, quien a propuesta de la fiscalía podría ser citado a declarar como testigo de oidas al juicio oral.

Las hipótesis de declaración ante la policía son clasificadas por el autor en declaración natural o espontánea, declaración voluntaria, y declaración provocada. Su exclusión probatoria o, en su caso, la valoración negativa que deberá realizar el tribunal, dependen por sobre todo de un determinado factor: si aquella manifestación la realizó un sospechoso o no, y si tuvo lugar ex ante o ex post de informado su derecho a guardar silencio. Con la expuesta viga matriz son medidos distintos contextos de declaración del encartado, así aquella vertida en momentos de un control de identidad o detención por flagrancia, la que tiene lugar ante el policía que toma la declaración por delegación del fiscal, la que se presta por el mismo agente con o sin la asistencia de un abogado defensor, entre otras erráticas y flexibles posibilidades.

Porque atan cabos sueltos sobre este tema y por su enorme repercusión práctica, dos aspectos contenidos en este trabajo merecen ser puestos de relieve. El primero, la opinión de este juez en torno al derecho a guardar silencio del imputado y sus condiciones de renuncia; y el segundo, la posibilidad de que el fiscal faculte de antemano a la policía para que le tome declaración al imputado mediante una instrucción general o particular. En este sentido, queda asentada la necesidad de fortalecer el hermético artículo 93 letra g) del Código Procesal Penal, añadiéndose como condición de renuncia - a la usanza norteamericana- el que el imputado puede renunciar a su garantía "...pero en tal evento, debe saber que todo lo que diga puede ser usado en su contra posteriormente" (pp. $46 \mathrm{y}$ 123). La última, derechamente es calificada de mala praxis, en la que el fiscal se excede de la facultad de delegación “...pues se debería demostrar previamente que el imputado, en primer lugar ya ha expresado su voluntad de declarar ante el fiscal, en segundo lugar que no cuenta con defensor que lo asista $y$, en tercer término que la policía ya hizo todo lo posible por hacer que el fiscal concurra a tomar la declaración del imputado, pues solo en tal evento se le permite al fiscal delegar tal actuación en la policía”, en caso contrario, podría excluirse al testigo-policía de oidas como prueba de cargo de cara al juicio oral, por cuanto tomó una declaración con base en una autorización antijurídica por anticipación (pp. 134-137).

En Cerda San Marín recayó la responsabilidad de dar forma a los últimos tramos de esta construcción a tres manos. Cumplió su cometido desarrollando la tríada de preguntas finales que dan vida al capítulo IV -sin perjuicio de su participación en los capítulos I y II precedentes-. El quid de esta postrimería radicó en la motivación fáctica de la sentencia, no ajena por su naturaleza, a los temas de la valoración de la prueba y el estándar probatorio. En mi opinión, la orientación otorgada constituyó un ejercicio paradigmático y armonioso de lo que el texto fue demostrando 
desde un principio: abstracción y aplicación en un movimiento pendular cuyo común denominador consiste en la aspiración de la racionalidad en el ejercicio de la jurisdicción, del proceso y de la prueba.

El acto procesal denominado sentencia definitiva adolece de un motivo de invalidación cuando falta en ella una exigencia consustancial: la fundamentación, la motivación suficiente, y en definitiva, la racionalidad. El ejercicio del poder en este desviado sentido rińe con la democracia y con las garantías del más emblemático de los justiciables: el imputado, resultando imposible su legitimación tanto respecto de las partes como de la sociedad.

Entendiendo que el Código adscribe a una concepción cognoscitivista y, por ende, racional de la prueba judicial -que se relaciona teleológicamente con la verdad-, este autor se preocupa sobre la necesidad de que la sentencia definitiva y otras resoluciones relevantes cuenten con la expresión de la secuencia racional adoptada tanto para la determinación de los hechos como para su calificación jurídica. Adoptando una distinción de Ferrer, estima que el tribunal cumple con el deber de motivación de su decisión cuando en forma completa y correcta, da a conocer "...con claridad las razones que tuvo para adoptarla, a través de la expresión de los tres momentos fundamentales de la decisión, esto es: a) la conformación del conjunto de elementos de prueba a valorar, b) la valoración de tales elementos, en forma individual y conjunta, determinando el grado de confirmación de las distintas hipótesis en conflicto, y c) la utilización del estándar de convicción” (pp. 391 y 401).

Sobre lo último, se nos explica que por imperativo jurídico y de racionalidad, entre los elementos de prueba y las proposiciones fácticas que se dan por probadas, debe existir un grado de corroboración que supere el estándar de probabilidad que en este caso corresponde al de la convicción más allá de toda duda razonable. Dicho estándar, recogido en el artículo 340 del Código Procesal Penal y que es concebido en términos objetivos, otorga el nivel de certeza necesario para vencer el estado de inocencia del acusado. Esta opción política-valorativa del legislador, en su concepto, opera en un momento metodológico posterior al de la valoración en sentido estricto, que previamente habrá permitido otorgar a cada hipótesis en conflicto un determinado grado de confirmación. Por la propia naturaleza asignada a este estándar, para este autor no existe una incompatibilidad entre los artículos 340 inciso $1^{\circ}$ y 297 del Código Procesal Penal, contribuyendo así al debate doctrinal originado sobre la posible antinomia de los preceptos.

Para el caso de incumplirse con la motivación fáctica, y en vistas a la obtención de la invalidación de la sentencia definitiva y el juicio oral precedente, este autor ahonda en el recurso de nulidad y la correcta causal a invocar por el recurrente. A su juicio, ello dependerá de la oportunidad y 
forma en que se produce el vicio que afecta al razonamiento fáctico de la sentencia definitiva. Un primer grupo de casos son aquellos que acaecen en el momento de la valoración probatoria, el otro tiene lugar con motivo de la aplicación del estándar de convicción. Respecto de los primeros, propone la causal del artículo 374 letra e) en relación con los artículos 342 letra c) y 297, todos del Código Procesal Penal, debiendo el tribunal ad quem, "efectuar una revisión exigente relativa a la existencia efectiva de la motivación (real y no meramente formal), así como la corrección del razonamiento utilizado de acuerdo a criterios de racionalidad" (p. 396). En el segundo caso, en su concepto, debería recurrirse por la causal contenida en el artículo 373 letra a) del Código Procesal Penal, sin perjuicio de la jurisprudencia de la Corte Suprema, la que se inclina por el artículo 374 letra e) en relación con los artículos 342 letra c), 297 y 340, todos del Código Procesal Penal.

Finalizando, celebro la recepción de la obra reseñada, cuyo semblante refleja experiencias propias de la implementación y funcionamiento de la reforma procesal penal en Chile. Su vocación, eminentemente pragmática sobre el fenómeno probatorio la torna altamente recomendable tanto para los intervinientes en un procedimiento de esta naturaleza, como para aquel que desempeña algún tipo de docencia universitaria, pues en ella coexiste un material cualitativa y cuantitativamente idóneo para ambos rubros, pudiendo aprovecharse en el segundo, para impartir conocimientos según las directrices de metodologías activas.

SEM SANDOVAL REYES*

Abogado, Licenciado en Ciencias Jurídicas, Universidad de Valparaíso (CHILE). Profesor ayudante de Derecho procesal, Escuela de Derecho Universidad de Valparaíso (Chile), correo electrónico: ssr@mackaycia.cl 